\title{
Neurofibromatosis type 1-related pseudarthrosis: Beyond the pseudarthrosis site
}

\author{
Carlijn Brekelmans $^{1}$ (i) | Silke Hollants ${ }^{2}$ | Caroline De Groote $^{2}$ | Natalie Sohier ${ }^{2}$ | \\ Marina Maréchal $^{3}$ | Liesbet Geris, ${ }^{4,5}$ | Frank P. Luyten ${ }^{3,6}{ }_{(0)}$ | Lieve Ginckels ${ }^{7}$ | \\ Raf Sciot $^{8,9}$ | Thomy de Ravel ${ }^{1,2}$ | Luc De Smet ${ }^{7,10}$ | Johan Lammens ${ }^{3,7}$ | \\ Eric Legius $^{1,2}$ | | Hilde Brems ${ }^{1,2}$ (1) \\ ${ }^{1}$ Department of Human Genetics, KU Leuven-University of Leuven, Leuven, Belgium \\ ${ }^{2}$ Clinical Department of Human Genetics, KU Leuven-University of Leuven, University Hospitals Leuven, Leuven, Belgium \\ ${ }^{3}$ Department of Development and Regeneration, Prometheus LRD Division of Skeletal Tissue Engineering, KU Leuven-University of Leuven, Leuven, Belgium \\ ${ }^{4}$ Department of Mechanical Engineering, Prometheus LRD Division of Skeletal Tissue Engineering, KU Leuven-University of Leuven, Leuven, Belgium \\ ${ }^{5} \mathrm{GIGA}$ In Silico Medicine, University of Liège, Liège, Belgium \\ ${ }^{6}$ Department of Rheumatology, KU Leuven-University Hospitals Leuven, Leuven, Belgium \\ ${ }^{7}$ Department of Orthopaedic Surgery, KU Leuven-University of Leuven, University Hospitals Leuven, Leuven, Belgium \\ ${ }^{8}$ Department of Imaging and Pathology, KU Leuven-University of Leuven, Leuven, Belgium \\ ${ }^{9}$ Department of Pathology, KU Leuven-University of Leuven, University Hospitals Leuven, Leuven, Belgium \\ ${ }^{10}$ Department of Development and Regeneration, KU Leuven-University of Leuven, Leuven, Belgium
}

\section{Correspondence}

Hilde Brems, Department of Human Genetics, KU Leuven - University of Leuven, Herestraat 49 - box 607, B-3000 Leuven, Belgium.

Email: hilde.brems@kuleuven.be

Funding information

Research Foundation Flanders (FWO), Grant/ Award Number: G.0588.12; Innovation by Science and Technology (IWT-Vlaanderen), Grant/Award Number: SB141185

\begin{abstract}
Neurofibromatosis type 1 (NF1) is an autosomal dominant disorder affecting approximately 1 in 2,000 newborns. Up to $5 \%$ of NF1 patients suffer from pseudarthrosis of a long bone (NF1-PA). Current treatments are often unsatisfactory, potentially leading to amputation. To gain more insight into the pathogenesis we cultured cells from PA tissue and normal-appearing periosteum of the affected bone for NF1 mutation analysis. PA cells were available from 13 individuals with NF1. Biallelic NF1 inactivation was identified in all investigated PA cells obtained during the first surgery. Three of five cases sampled during a later intervention showed biallelic NF1 inactivation. Also, in three individuals, we examined periosteum-derived cells from normal-appearing periosteum proximal and distal to the PA. We identified the same biallelic NF1 inactivation in the periosteal cells outside the PA region. These results indicate that NF1 inactivation is required but not sufficient for the development of NF1-PA. We observed that late-onset NF1-PA occurs and is not always preceded by congenital bowing. Furthermore, the failure to identify biallelic inactivation in two of five later interventions and one reintervention with a known somatic mutation indicates that NF1-PA can persist after the removal of most NF1 negative cells.
\end{abstract}

KEYWORDS

biallelic inactivation, neurofibromatosis type 1, periosteum, pseudarthrosis, RAS/MAPK pathway 


\section{1 | INTRODUCTION}

Neurofibromatosis type 1 (NF1) is an autosomal dominantly inherited disorder affecting approximately 1 in 2,000 newborns (MIM\# 162200; Uusitalo et al., 2015). NF1 is caused by an inactivating mutation in the NF1 gene, encoding neurofibromin, a negative regulator of the RAS/MAPK pathway. The mutational spectrum of NF1 is broad and mutation hotspots are not present (Messiaen et al., 2000; van Minkelen et al., 2014). In recent years, several clinical features of NF1, including the distinctive café-aulait macules and neurofibromas, were shown to be caused by biallelic NF1 inactivation in a specific cell type (De Schepper et al., 2008; Serra et al., 2000). Besides the more common clinical features, individuals with NF1 are prone to several bone disorders (Monroe, Dahiya, \& Gutmann, 2017). Osteoporosis, osteopenia, scoliosis, sphenoid wing dysplasia and pseudarthrosis (PA) of the long bones are associated with NF1 (Stevenson et al., 2013). Up to $5 \%$ of individuals with NF1 are reported to develop a PA (Friedman \& Birch, 1997; Schindeler \& Little, 2008; Young, Hyman, \& North, 2002). The NF1-related PA is often preceded by the congenital bowing of the long bone, the subsequent fracture is difficult to treat and leads to PA. NF1-related PA occurs most often in the tibia but other long bones, such as the fibula, ulna, and radius, may also be affected (Ramelli, Slongo, Tschappeler, \& Weis, 2001; Stevenson et al., 1999). Several treatments for NF1related PA are currently in use. However, regardless of the treatment method used, union at the PA site often remains elusive and refractures occur frequently (Horn, Steen, \& Terjesen, 2013; Vanderstappen, Lammens, Berger, \& Laumen, 2015). Therefore, amputation of the affected limb is still a potential outcome (Horn et al., 2013; Stevenson et al., 1999; Vanderstappen et al., 2015).

PA tissue was shown to contain biallelic NF1 inactivation in approximately $65 \%$ of the published cases (S. M. Lee et al., 2012; Paria et al., 2014; Sakamoto et al., 2007; Sant et al., 2015; Stevenson et al., 2006). However, some were examined using only microsatellite marker analyses of NF1, this being suitable to detect copy number variations within NF1 but not point mutations or small insertions and deletions. Why no somatic NF1 mutation is detected in all NF1 related PA tissues examined by regular NF1 mutation analysis or whole exome sequencing is still unknown, although the sensitivity of the method and available tissue is of influence. The affected cell type and the pathogenetic mechanism responsible for PA development and persistence also remains to be discovered.

The periosteum is known to play an important role in osteogenesis, both during development and fracture repair (Hutmacher \& Sittinger, 2003; Park et al., 2017; Roberts, van Gastel, Carmeliet, \& Luyten, 2014). Furthermore, cultured PA cells show similar characteristics to mesenchymal lineage cells derived from periosteum of control individuals (Cho et al., 2008). Therefore we extended our analysis beyond cells from the PA region, to cells from the normalappearing proximal and distal periosteum. Our results show that the
NF1-related PA is a complex and likely multifactorial problem in both young and adult individuals, with biallelic NF1 inactivation involving the periosteum beyond the PA site. We remarkably observed NF1PA in previously normally appearing bones in adults.

\section{2 | METHODS AND MATERIALS}

\subsection{Editorial policies and ethical considerations}

Tissues were obtained after informed consent. This study was approved by the Ethical Committee of the University Hospitals Leuven (study reference number: S53799).

\subsection{Cell culture}

During surgery, biopsies were taken from the PA tissue, without identifiable periosteum present. Three individuals were sampled extensively, besides several PA biopsies normal-appearing periosteum directly proximal and distal to the PA site was sampled using a Bistouri and tweezers. In two individuals a small periosteum biopsy was taken at the osteotomy site, the proximal $1 / 3 r d$ of the tibia, using an up bite Kerrison clamp. Since the biopsies were small, cells were initially cultured. The tissues were dissociated overnight at $37^{\circ} \mathrm{C}$ using $160 \mathrm{U} / \mathrm{ml}$ collagenase (catalog no. C0130; Sigma, Herent, Belgium) and $0.8 \mathrm{U} / \mathrm{ml}$ dispase (catalog no. 10241750001; Roche, Anderlecht, Belgium). PA and periosteum-derived cells (PDCs) were cultured in Dulbecco's modified Eagle medium (catalog no. 41966-029; Invitrogen, Gent, Belgium) supplemented with $10 \%$ fetal bovine serum (catalog no. $\mathrm{SH}$ 30071.03; Hyclone, Loncin, Belgium) and $1 \%$ penicillinstreptomycin (catalog no. 15140-122; Invitrogen). Both PA cells and PDCs grow adherent, are mostly bipolar, have an elongated shape and grow in culture as fibroblast-like cells.

\section{3 | Histopathology}

When available, biopsies obtained from the PA site were pathologically examined. Sections of PA tissue were stained with hematoxylin and eosin following standard protocol. Also, immunostaining was performed on several PA samples for CD34 (clone QBEnd10; Dako, Leuven, Belgium), CD44 (clone DF1485; Dako), and CD45 (clone 2B11+PD7/26; Dako)

\subsection{DNA isolation}

DNA was isolated from the cultured cells between cell culture passage 3 and 7 depending on the biopsy size, and in one case freshly frozen PA tissues, using the QIAamp DNA mini kit (catalog no. 51304; Qiagen, Venlo, The Netherlands). The isolation was performed according to the manufacturer's instructions. 


\section{5 | RNA isolation}

RNA was isolated from puromycin-treated cultured cells, between cell culture passage 3 and 7 depending on the biopsy size, using the RNeasy Mini kit (catalog no. 74104; Qiagen). The isolation was performed according to the manufacturer's instructions. This RNA was used for NF1 copy DNA (cDNA) mutation analysis.

\subsection{Flow cytometry and qPCR}

Using flow cytometry CD34 (catalog no. 560710; BD biosciences, Erembodegem, Belgium), CD44 (catalog no. 560531; BD biosciences), and CD45 (catalog no. 17-9459-42; eBioscience, San Diego, CA) expression in cultured PA and periosteum cells was assessed. Shortly, 200,000 cells were incubated for 20 min with a 1 in 100 antibody dilution in PBS at room temperature, washed twice with PBS and strained before measuring.

Real-time quantitative PCR was performed on RNA using SYBR green I (catalog no. 04707516001; Roche Diagnostics, Vilvoorde, Belgium). RANKL expression was determined on cultured PA and periosteum cells.

\section{7 | Mutation analysis}

NF1 mutation screening (LRG_214) was performed on cDNA from cultured PA cells. These cells were puromycin-treated, subsequently, mRNA was extracted and used for cDNA synthesis. NF1 sequencing was performed as described previously (Messiaen et al., 2000). Identified mutations were confirmed on genomic DNA. Intragenic deletions and duplications were examined using multiplex ligationdependent probe amplification (catalog no. P081-NF1 mix 1 and P082-NF1 mix 2; MRC-Holland, Amsterdam, The Netherlands) according to manufacturer's instructions. If no somatic NF1 mutation was identified in the cultured PA cells, the HaloPlex Noonan syndrome kit was used (made to order; Agilent, Leuven, Belgium) according to manufacturer's instructions, since this has a lower detection threshold than the classical method. Pathogenicity of mutations was interpreted according to ACMG guidelines. Genomic DNA from cultured lymphocytes or buccal swabs was used to identify the germline mutation. If available, DNA from cultured PDCs was sequenced to examine the presence of the previously identified somatic NF1 mutation.

In two of the three individuals sampled extensively, deep sequencing for the identified somatic mutation was performed on the Illumina MiSeq platform (Illumina, Brussels, Belgium) using $250 \mathrm{bp}$ paired end reading. Results were analyzed in the JSI SeqNext software (JSI Medical Systems, Ettenheim, Germany). Using this software the number of reads for the wildtype and mutated nucleotide(s) was determined and correlated with the percentage of cells carrying a somatic mutation.

Cells from one individual were subjected to SNParray since mitotic recombination was suspected. The HumanCytoSNP-12v2.1 array (WG-320-2102; Illumina) was performed according to the
Infinium II Assay Multi-Sample protocol. Results were analyzed in GenomeStudio (Illumina).

All identified NF1 mutations were submitted to the Leiden Open Variation Database (https://databases.lovd.nl/shared/genes/NF1).

\section{3 | RESULTS}

\section{1 | Biallelic NF1 inactivation detected in cultured PA cells}

In total, PA cells of 13 individuals with NF1-related PA were analyzed to identify the NF1 status. The germline NF1 mutation was identified in all individuals (Table 1). Of the identified germline mutations one was a splice-site, four were known pathogenic missense, one was a nonsense and six were frameshift mutations. One individual had a multiexon deletion (exon 2-25) causing NF1 inactivation. Two individuals, not known to be closely related and both de novo cases, had identical germline mutations (Table 1 , individuals $E$ and $F$; c.499_502del, p.Cys167Glnfs*10).

Eight of 13 individuals were sampled during the first surgery for NF1-PA (primary). Five individuals were sampled during reintervention whereby PA tissue was resected (later), with one or more earlier resections of PA tissue unavailable for analysis. In all eight individuals with cultured primary PA cells available, we found biallelic NF1 inactivation (Table 1, individuals $A$ to $H$ ). Of the five individuals in whom only cultured PA cells from a later surgery were examined (later), we identified an additional somatic NF1 inactivation in three (Table 1, individuals I to M). One individual with biallelic NF1 inactivation detected in primary PA cells underwent two reinterventions (Table 1, individual G). Only $3 \%$ of PA cells, of freshly frozen biopsy, from the first reintervention had the previously detected somatic NF1 mutation, detectable by deep sequencing only (Table S1). In seven biopsies from the PA region taken during the second reintervention, analyzed on fresh frozen biopsies, the percentage of cells with biallelic NF1 inactivation was between $0 \%$ and $1 \%$ (Table S2). We identified 11 somatic NF1 mutations. Of these, one was a splice-site, two were known pathogenic missense, four were nonsense and three were frameshift mutations. One individual had copy-neutral loss of heterozygosity caused by somatic recombination on the long arm of chromosome 17 leading to homozygosity for the germline NF1 mutation in the PA cells (Table 1, individual F; Figure S1). The NF1 mutations identified, both germline and somatic, are found throughout the NF1 gene and are not concentrated in an obvious hotspot region (Table 1).

Of the 13 individuals with NF1-related PA examined, four were female and nine were male (not significant binomial distribution). The tibia was affected in 10 of 13 cases whilst the fibula (solely, without the involvement of the tibia), ulna and radius were all affected once in our cohort (Table 1, individuals D, E, and H). All three also showed biallelic NF1 inactivation.

Pathological examination of the available PA samples showed that the PA sites mostly consisted of connective tissue, with differing degrees of cellularity and vascularity with the presence of 
TAB LE 1 NF1 mutations (pathogenic or likely pathogenic according to ACMG guidelines) in cells of pseudarthrosis tissue obtained during the first surgery (primary; individual $\mathrm{A}$ to $\mathrm{H}$ ) or reintervention (later; individual I to $\mathrm{M}$ ). Individual $\mathrm{G}$ was also sampled during a reintervention (primary+later)

\begin{tabular}{|c|c|c|c|c|c|c|c|c|}
\hline \multirow[b]{2}{*}{ Individual } & \multirow[b]{2}{*}{ Sex } & \multirow[b]{2}{*}{ Age } & \multirow[b]{2}{*}{ Location } & \multirow[b]{2}{*}{ Intervention } & \multicolumn{2}{|c|}{ NF1 Germline mutation } & \multicolumn{2}{|c|}{ NF1 Somatic mutation } \\
\hline & & & & & DNA level & Protein level & DNA level & Protein level \\
\hline A & Male & 5 years & Tibia & Primary & c.1182dup & p.(Lys395*) & c. $245 C>T$ & p.(Ser82Phe) \\
\hline C & Male & 2 years & Tibia & Primary & c.3571dup & p.(Thr1191Asnfs*4) & c. $4367+1 G>A$ & p.lle1424Valfs* $4^{a}$ \\
\hline D & Male & 6 years & Ulna & Primary & c. $4267 A>C$ & p.(Lys1423GIn) & c. $5430 \mathrm{G}>\mathrm{A}$ & p.Trp1810* \\
\hline $\mathrm{F}$ & Female & 4 years & Tibia & Primary & c.499_502del & p.Cys167GInfs*10 & $\mathrm{cnLOH}^{\mathrm{b}}$ & p.Cys167GInfs*10 \\
\hline G & Male & 4 years & Tibia & $\begin{array}{l}\text { Primary } \\
\text { +later }\end{array}$ & $\begin{array}{l}\text { c.(60+598_92)_ } \\
\left(4349 \_4433\right) \mathrm{del}\end{array}$ & Deletion ex 2-25 & c. $3916 C>T$ & p.Arg1306* \\
\hline $\mathrm{H}$ & Female & 8 years & Radius & Primary & c. $1466 A>G$ & p.Tyr489* & c. $7365 T>A$ & p.(Tyr2455*) \\
\hline I & Male & 47 years & Tibia & Later & c. $1299 \mathrm{~T}>\mathrm{G}$ & p. $($ Tyr433*) & c. $3827 \mathrm{G}>\mathrm{A}$ & p.(Arg1276GIn) \\
\hline M & Female & 3 years & Tibia & Later & c. $2540 \mathrm{~T}>\mathrm{C}$ & p.Leu847Pro & ND & ND \\
\hline
\end{tabular}

Abbreviations: cnLOH, copy neutral loss of heterozygosity; ND, not detected; NF1, neurofibromatosis type 1.

Note. Reference: LRG_214 t1 (NM_000267.3) and LRG_214 p1.

${ }^{\mathrm{a}}$ splice site mutation.

${ }^{b}$ more information in Figure S1.

small deposits of adipose-tissue, chondrogenic tissue and sometimes mineralization. Two samples showed a few focal osteoclasts, which were not in the vicinity of bone (Figure S2). Staining for CD markers showed that the PA tissue did not express CD45, some samples expressed CD34 and most had high expression of CD44, most prominently in cell-dense regions (Figure S3). CD34 is expressed by hematopoietic stem cells; CD44 is involved in cell-cell interactions, adhesion and migration and expressed by, among others, mesenchymal stem cells and CD45 is expressed by hematopoietic lineage cells. These results were confirmed using flow cytometry on cultured cells (Figure S4). In addition, RANKL expression was examined in these samples but did not illustrate a correlation between the NF1 inactivation and RANKL expression. There was large variability in expression between samples of the same genotype (Figure S5).

\section{2 | Late-onset NF1-related PA}

Three individuals presented with late-onset tibial PA with an atypical clinical history (Table 1 individuals B [52 years], I [47 years], and K [17 years]). Individual B presented with adult-onset fibular PA. Upon radiographic examination, slight anterolateral bowing of the tibia was visible with cortical thickening (Figure $\mathrm{S6}$ ). Treatment of the fibular PA preceded the tibia fracture and subsequent PA. Individual I had a tibial osteotomy to correct bowing at 35 years of age, without further problems. However, at 45 years a tibial PA developed. Individual $\mathrm{K}$ had anterolateral tibial bowing since childhood, with a distal fibular PA. At 17 years a proximal tibial fracture and subsequent PA developed (Table S3). In all of these individuals, an additional somatic NF1 inactivation was identified in PA cells of the tibial PA tissue (Table 1, individuals $\mathrm{B}, \mathrm{I}$, and $\mathrm{K}$ ).

\section{3 | Biallelic NF1 inactivation in periosteal-derived cells outside the PA site}

Three of eight individuals were sampled more extensively during their first surgery (Figure 1; Table 1, individuals $F$ to $H$ ). For each individual several biopsies were taken from the PA. In addition, the normal-appearing periosteum directly distal and proximal to the PA site was also sampled. If the tibia was affected periosteum from the proximal osteotomy site was biopsied, the minimum distance between the PA site and osteotomy site was 5.8 and $3.6 \mathrm{~cm}$ for individual $F$ and $G$ respectively. The biopsies were cultured, RNA and DNA were extracted and genetic analysis was performed. Between $4 \%$ and $97 \%$ of cells carry a somatic NF1 mutation in the PA tissue. This varied between individuals and between samples of the same PA site (Table 2). For the tibiae (Table 2, individual F and G; Tables S1 and S4) $77 \%$ and $92 \%$ of PDCs distal to the PA site have biallelic NF1 inactivation. While proximal to the PA only $33 \%$ and $17 \%$ of cells were affected. Cultured periosteum samples from the proximal osteotomy site still contained $32 \%$ and $2 \%$ of PDCs with a biallelic NF1 inactivation. For the radius sampled (Table 2 , individual $H$ ) the somatic NF1 inactivation was seen in $76 \%$ of PDCs proximal to the PA site, while distally this was limited to $15 \%$. 


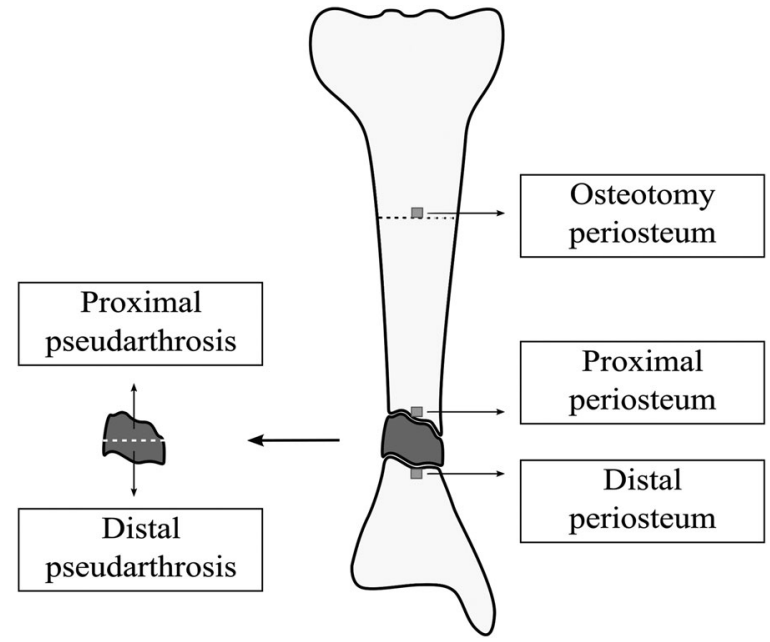

FIGURE 1 Schematic representation of extensive pseudarthrosis (PA) and periosteum sampling of the tibia. During extensive sampling, several samples from the pseudarthrosis site were taken. The normal-appearing periosteum directly proximal and distal to the PA site was sampled. Also, a small periosteum biopsy was taken at the osteotomy site (at the proximal $1 / 3 r d$ of the tibia, for scientific purposes)

\section{4 | DISCUSSION}

We show that biallelic NF1 inactivation is needed for a PA to develop because it was identified in all PA samples obtained during the first surgery. Moreover, a detectable level of cells with biallelic NF1 inactivation, using current techniques, is not required for a PA to persist. In PA tissue harvested during reintervention, biallelic NF1 inactivation was not detected in only two of five cases examined.

One NF1-PA case had, besides the PA cells from the primary surgery, two reinterventions (individual G, Table 1). In PA cells from the primary surgery, the somatic NF1 mutation was identified, which was also present in PDCs from normal-appearing periosteum.

TABLE 2 Percentage of cultured cells carrying a somatic NF1 inactivation detected in the samples taken from several individuals during extensive sampling. Dashes separate the percentage of NF1 inactivation found between several samples taken at the same location.

\begin{tabular}{|llll|}
\hline & $\begin{array}{l}\text { Individual F } \\
\text { Tibia }\end{array}$ & $\begin{array}{l}\text { Individual G } \\
\text { Tibia }\end{array}$ & $\begin{array}{l}\text { Individual H } \\
\text { Radius }\end{array}$ \\
\hline $\begin{array}{c}\text { Osteotomy } \\
\text { periosteum }\end{array}$ & $32 \%$ & $2 \%$ & NS \\
$\begin{array}{c}\text { Proximal } \\
\text { periosteum }\end{array}$ & $33 \%$ & $17 \%$ & $76 \%$ \\
\hline Proximal PA & $7-30-94 \%$ & $42 \%$ & $72-78 \%$ \\
\hline Middle PA & NS & NS & $72-90 \%$ \\
\hline Distal PA & $34-97 \%$ & $4 \%$ & $61-85 \%$ \\
\hline Distal periosteum & $77 \%$ & $92 \%$ & $15 \%$ \\
\hline
\end{tabular}

Abbreviations: NF1, neurofibromatosis type 1; NS, not sampled; PA, pseudarthrosis.
Samples from subsequent interventions were therefore tested using deep sequencing. In PA tissue from the first reintervention (using iliac crest grafting, whereby the PA site was cleared of fibrous tissue) only $3 \%$ of the cells had biallelic NF1 inactivation (Table S1), while PA tissue biopsies from the second reintervention (intramedullary TEN nailing after the second refracture), where DNA was extracted directly without cell culture, contained 0 to $1 \%$ of cells with the somatic NF1 inactivation (Tables S2 and S3). Thus, the virtual complete clearing of NF1 negative cells from the PA site is not sufficient to promote union. This, for the first time, explains why biallelic NF1 inactivation is not always detected in NF1-related PA tissue obtained at surgery subsequent to the first intervention. Although it must be noted that cell culture might influence the exact percentage of cells with biallelic NF1 inactivation detected (not applicable in this case, because mutation analysis was carried out on tissue biopsies without culture), as does bone grafting at the PA site possibly influence the percentage of cells with biallelic NF1 mutations found (second reintervention in this case). Larger PA and periosteum biopsies would, therefore, be preferable, since direct DNA extraction without culture would then be possible. However, due to the young age of most patients and the central role of periosteum in bone repair, this would be irresponsible.

In our patient cohort, we see a slight but not significant predominance of males in line with what was previously described in the literature (Stevenson et al., 1999). Although tibial PA was by far the most frequent location for an NF1-related PA to develop in our patient cohort, we also observed for the first time biallelic NF1 inactivation in NF1-PA of other long bones: ulna, fibula, and radius (x-rays in Figure S6). In the individual with an affected radius, cells from the normalappearing periosteum showed the same somatic NF1 mutation as found in the PA cells. This indicates that NF1-related PA in locations other than the tibia shares the same underlying pathogenetic mechanism.

Of the 13 individuals sampled, three had late-onset tibial PA (Table 1, individuals B, I, and K). NF1-related PA is reported in the literature as a pediatric problem that occurs associated with congenital bowing of the affected long bone. These cases, however, prove that adults affected with NF1 can still be at risk of developing a PA, even without clinically observable prior bowing of the involved bone. It must, however, be noted that individuals with NF1 were shown to have an altered lower leg geometry, even without PA (Stevenson et al., 2009). This was however not studied in these cases. The pathogenesis underlying late-onset NF1-related PA also seems to be mediated by biallelic NF1 inactivation.

For the first time, it was shown that the somatic NF1 mutation in NF1-related PA cases is not confined to the PA site only, but is also present throughout the periosteum of the affected bone. This is also the first direct evidence that the periosteum is involved in the pathogenesis of NF1-related PA, which was previously hypothesized (Cho et al., 2008; S. M. Lee et al., 2012; Sakamoto et al., 2007; Sant et al., 2015). The exact role of the periosteal cells is still unclear. Periosteum-grafting has been reasonably successful in treating NF1-PA (Thabet et al., 2008). This indicates the importance of gaining more insight into the effect of NF1 inactivation on periosteal-derived cells. 
The fact that biallelic NF1 inactivation can be found in normalappearing periosteum throughout the affected bone suggests that additional factors are needed for a PA to develop. For the tibia, blood supply is lowest in the distal $1 / 3$ rd of the bone and this section is surrounded by the least amount of muscle tissue (Menck, Bertram, Lierse, \& Wolter, 1992). In addition, mechanical stress is highest in the distal 1/3rd of the tibia (Charnley, 1956; McFarland, 1950). These are likely local factors aiding in the initiation and possibly maintenance of the PA. The lack of cells with a somatic NF1 inactivation from the PA site during reinterventions suggests the involvement of additional (local) factors for the maintenance of the PA. These could be the same as the ones needed for PA development, or additional factors such as microenvironment changes brought on by the initial PA tissue and/or altered chronic inflammatory responses. Furthermore increased numbers of osteoclasts and increased RANKL production could increase (local) bone catabolism (Heervä et al., 2010; Park et al., 2017; Schindeler \& Little, 2008). However, in the studied samples, osteoclast infiltration and increased RANKL production were not detected in the PA tissue and cells, though this might be due to the relatively small sample size available. Currently, it is not clear which additional (local) factors are involved in NF1-PA initiation and maintenance and what is their exact role.

The analysis of several samples from the same PA region illustrates the heterogeneity of this tissue. It shows that the percentage of cells carrying a somatic NF1 mutation within the PA tissue is highly variable and that the somatic NF1 inactivation can easily be missed due to limited sampling of the PA tissue. The heterogeneity of the PA tissue and the presence of biallelic NF1 inactivation in periosteum tissue outside the PA region makes it difficult to correlate the percentage of somatic NF1 inactivation present in the PA with the severity of the PA and possible success of treatment. However, individual F, who had the highest percentage of biallelic NF1 inactivated PDCs at the osteotomy site, did have the worst clinical outcome (amputation). To gain more insight into a possible correlation between NF1 inactive cells and the severity of the PA it is advisable to sample more NF1-related PA cases and sample them more extensively.

The complex pathogenesis of NF1-PA makes it difficult to model, although several attempts have been made in the past. Mouse models (partly) recapitulate the genetics behind NF1-PA and model delayed fracture healing (El Khassawna et al., 2012; El-Hoss et al., 2012; Wu et al., 2011). Spontaneous PA development does however not occur in these models. Human NF1-related bone stromal cells were tested and found to have elevated ENPP1 expression (de la Croix Ndong et al., 2014). RNA sequencing discovered a tumorpromoting transcriptional pattern in PA cells, however, there was a variable degree of biallelic inactivation in the samples tested (Paria et al., 2014). Human and mouse NF1 deficient cells examined in vitro showed reduced osteogenic differentiation (El-Hoss et al., 2012; D. Y. Lee et al., 2011; Leskelä et al., 2009; Zhang et al., 2011). However, human biallelic NF1 inactivated PA and periosteal cells have yet to be characterized in functional studies.

In summary, the obtained results indicate that biallelic NF1 inactivation is required but not sufficient for a PA to develop.
Also, the persistence of NF1-PA does not rely solely on the presence of NF1 negative cells. NF1 mutations detected in PA cells were mostly small nucleotide changes. Furthermore, we report for the first time that NF1-related PA can have a late onset and does not necessarily need to be preceded by congenital bowing. Both types of NF1-PA are associated with biallelic NF1 inactivation. Within our patient cohort, we had a slight predominance of males and the tibia was the bone most often affected. NF1-related PA in other long bones (fibula, ulna, and radius) shares the same biallelic NF1 inactivation. The somatic NF1 mutations in periosteal-derived cells indicate the involvement of periosteum in the pathogenesis of NF1-related PA, although the exact mechanism is still not clear. The expressed CD markers do point to a mesenchymal stem cell-like lineage of the PA cells, which is indicative of a periosteum origin. NF1 inactivation of PDCs, being an important source of stem cells for osteoblasts during fracture repair, is likely to influence the osteogenic differentiation of these cells. Heterozygous NF1 inactivation in osteoclasts is known to increase their number at the PA site as well as their resorption activity (Heervä et al., 2010; Schindeler \& Little, 2008). The combination of these factors could contribute to the persistence of PA due to the stimulatory effect on bone catabolism. This could however not be proven on the samples we studied, because no increase in osteoclasts was observed. Therefore functional characterization of human NF1 inactivated periosteal-derived cells is essential. The results presented here illustrate the complex pathogenesis underlying NF1-related PA. A better understanding of this pathogenesis is an important step towards improved treatment of this severe orthopedic problem.

\section{ACKNOWLEDGMENTS}

This study was supported by a grant from the Research Foundation Flanders (FWO) (G.0588.12). C.B. received a PhD grant (SB141185) from the agency for Innovation by Science and Technology (IWTVlaanderen). The authors would like to thank Kathleen Bosmans and Carla Geeroms (KU Leuven-The University of Leuven, Department of Development and Regeneration, Prometheus LRD division of skeletal tissue engineering) for their practical work. The authors would like to thank Prof. Jan Cools and Kris Jacobs (VIB-KU LeuvenThe University of Leuven, Department of Molecular Biology of Leukemia) for their guidance, equipment, and antibodies during the flow cytometry experiments.

\section{ORCID}

Carlijn Brekelmans (D) http://orcid.org/0000-0003-0652-107X Liesbet Geris (D) http://orcid.org/0000-0002-8180-1445 Frank P. Luyten (D) http://orcid.org/0000-0003-3186-0276 Raf Sciot (D) http://orcid.org/0000-0003-2244-5839 Eric Legius (D) http://orcid.org/0000-0003-2410-6996 Hilde Brems (D) http://orcid.org/0000-0002-0325-4060 


\section{REFERENCES}

Charnley, J. (1956). Congenital pseudarthrosis of the tibia treated by the intramedullary nail. The Journal of Bone \& Joint Surgery 38-A(2), 283-290.

Cho, T., Seo, J., Lee, H. R., Yoo, W. J., Chung, C. Y., \& Choi, I. H. (2008). Biologic characteristics of fibrous hamartoma from congenital pseudarthrosis of the tibia associated with neurofibromatosis type 1. The Journal of Bone \& Joint Surgery, 90(12), 2735-2744.

de la Croix Ndong, J., Makowski, A. J., Uppuganti, S., Vignaux, G., Ono, K., Perrien, D. S., \& Elefteriou, F. (2014). Asfotase- $\alpha$ improves bone growth, mineralization and strength in mouse models of neurofibromatosis type-1. Nature Medicine, 20, 904-910.

De Schepper, S., Maertens, O., Callens, T., Naeyaert, J.-M., Lambert, J., \& Messiaen, L. (2008). Somatic mutation analysis in NF1 café au lait spots reveals two NF1 hits in the melanocytes. The Journal of Investigative Dermatology, 128(4), 1050-1053.

El Khassawna, T., Toben, D., Kolanczyk, M., Schmidt-Bleek, K., Koennecke, I., Schell, H., \& Duda, G. N. (2012). Deterioration of fracture healing in the mouse model of NF1 long bone dysplasia. Bone, 51(4), 651-660.

El-Hoss, J., Sullivan, K., Cheng, T., Yu, N. Y. C., Bobyn, J. D., Peacock, L., \& Little, D. G. (2012). A murine model of neurofibromatosis type 1 tibial pseudarthrosis featuring proliferative fibrous tissue and osteoclast-like cells. Journal of Bone and Mineral Research: The Official Journal of the American Society for Bone and Mineral Research, 27(1), 68-78.

Friedman, J. M., \& Birch, P. H. (1997). Type 1 neurofibromatosis: A descriptive analysis of the disorder in 1,728 patients. American Journal of Medical Genetics, 70(2), 138-143.

Heervä, E., Alanne, M. H., Peltonen, S., Kuorilehto, T., Hentunen, T., Väänänen, K., \& Peltonen, J. (2010). Osteoclasts in neurofibromatosis type 1 display enhanced resorption capacity, aberrant morphology, and resistance to serum deprivation. Bone, 47(3), 583-590.

Horn, J., Steen, H., \& Terjesen, T. (2013). Epidemiology and treatment outcome of congenital pseudarthrosis of the tibia. Journal of Children's Orthopaedics, 7(2), 157-166.

Hutmacher, D. W., \& Sittinger, M. (2003). Periosteal cells in bone tissue engineering. Tissue Engineering, 9(Suppl 1), 45-64.

Lee, D. Y., Cho, T.-J., Lee, H. R., Lee, K., Moon, H. J., Park, M. S., \& Choi, I. H. (2011). Disturbed osteoblastic differentiation of fibrous hamartoma cell from congenital pseudarthrosis of the tibia associated with neurofibromatosis type I. Clinics in Orthopedic Surgery, 3(3), 230-237.

Lee, S. M., Choi, I. H., Lee, D. Y., Lee, H. R., Park, M. S., Yoo, W. J., \& Cho, T. (2012). Is double inactivation of the Nf1 gene responsible for the development of congenital pseudarthrosis of the tibia associated with NF1? Journal of Orthopaedic Research, 30(10), 1535-1540.

Leskelä, H. V., Kuorilehto, T., Risteli, J., Koivunen, J., Nissinen, M., Peltonen, S., \& Peltonen, J. (2009). Congenital pseudarthrosis of neurofibromatosis type 1: Impaired osteoblast differentiation and function and altered NF1 gene expression. Bone, 44(2), 243-250.

McFarland, B. (1950). Pseudarthrosis of the tibia in childhood. The Journal of Bone \& Joint Surgery, 33B(1), 36-46.

Menck, J., Bertram, C., Lierse, W., \& Wolter, D. (1992). Das arterielle versorgungsprinzip der tibia und seine praktischen konsequenzen. Langenbecks Archiv für Chirurgie, 377(4), 229-234.

Messiaen, L. M., Callens, T., Mortier, G., Beysen, D., Vandenbroucke, I., van Roy, N., \& De Paepe, A. (2000). Exhaustive mutation analysis of the NF1 gene allows identification of $95 \%$ of mutations and reveals a high frequency of unusual splicing defects. Human Mutation, 15(6), 541-555.
Monroe, C. L., Dahiya, S., \& Gutmann, D. H. (2017). Dissecting clinical heterogeneity in neurofibromatosis type 1. Annual Review of Pathology: Mechanisms of Disease, 12, 53-74.

Paria, N., Cho, T.-J., Choi, I. H., Kamiya, N., Kayembe, K., Mao, R., \& Rios, J. J. (2014). Neurofibromin deficiency-associated transcriptional dysregulation suggests a novel therapy for tibial pseudoarthrosis in NF1. Journal of Bone and Mineral Research, 29(12), 2636-2642.

Park, H. C., Son, Y. B., Lee, S. L., Rho, G. J., Kang, Y. H., Park, B. W., \& Byun, J. H. (2017). Effects of osteogenic-conditioned medium from human periosteum-derived cells on osteoclast differentiation. International Journal of Medical Sciences, 14(13), 1389-1401.

Ramelli, G. P., Slongo, T., Tschappeler, H., \& Weis, J. (2001). Congenital pseudarthrosis of the ulna and radius in two cases of neurofibromatosis type 1. Pediatric Surgery International, 17, 239-241.

Roberts, S. J., van Gastel, N., Carmeliet, G., \& Luyten, F. P. (2014). Uncovering the periosteum for skeletal regeneration: The stem cell that lies beneath. Bone, 70, 10-18.

Sakamoto, A., Yoshida, T., Yamamoto, H., Oda, Y., Tsuneyoshi, M., \& Iwamoto, Y. (2007). Congenital pseudarthrosis of the tibia: Analysis of the histology and the NF1 gene. Journal of Orthopaedic Science, 12(4), 361-365.

Sant, D. W., Margraf, R. L., Stevenson, D. A., Grossmann, A. H., Viskochil, D. H., Hanson, H., \& Mao, R. (2015). Evaluation of somatic mutations in tibial pseudarthrosis samples in neurofibromatosis type 1. Journal of Medical Genetics, 52(4), 256-261.

Schindeler, A., \& Little, D. G. (2008). Recent insights into bone development, homeostasis, and repair in type 1 neurofibromatosis (NF1). Bone, 42(4), 616-622.

Serra, E., Rosenbaum, T., Winner, U., Aledo, R., Ars, E., Estivill, X., \& Lázaro, C. (2000). Schwann cells harbor the somatic NF1 mutation in neurofibromas: Evidence of two different Schwann cell subpopulations. Human Molecular Genetics, 9(20), 3055-3064.

Stevenson, D. A., Birch, P. H., Friedman, J. M., Viskochil, D. H., Balestrazzi, P., Boni, S., \& Carey, J. C. (1999). Descriptive analysis of tibial pseudarthrosis in patients with neurofibromatosis 1. American Journal of Medical Genetics, 84(5), 413-419.

Stevenson, D. A., Zhou, H., Ashrafi, S., Messiaen, L. M., Carey, J. C., D'Astous, J. L., \& Viskochil, D. H. (2006). Double inactivation of NF1 in tibial pseudarthrosis. American Journal of Human Genetics, 79(1), 143-148.

Stevenson, D. A., Viskochil, D. H., Carey, J. C., Slater, H., Murray, M., Sheng, X., \& Moyer-Mileur, L. J. (2009). Tibial geometry in individuals with neurofibromatosis type 1 without anterolateral bowing of the lower leg using peripheral quantitative computed tomography. Bone, 44(4), 585-589.

Stevenson, D. A., Little, D., Armstrong, L., Crawford, A. H., Eastwood, D., Friedman, J. M., \& Elefteriou, F. (2013). Approaches to treating NF1 tibial pseudarthrosis: Consensus from the Children's Tumor Foundation NF1 bone abnormalities consortium. Journal of Pediatric Orthopedics, 33(3), 269-275.

Thabet, A. M., Paley, D., Kocaoglu, M., Eralp, L., Herzenberg, J. E., \& Ergin, O. N. (2008). Periosteal grafting for congenital pseudarthrosis of the tibia: A preliminary report. Clinical Orthopaedics and Related Research, 466(12), 2981-2994.

Uusitalo, E., Leppavirta, J., Koffert, A., Suominen, S., Vahtera, J., Vahlberg, T., \& Peltonen, S. (2015). Incidence and mortality of neurofibromatosis: A total population study in Finland. Journal of Investigative Dermatology, 135(3), 904-906.

van Minkelen, R., van Bever, Y., Kromosoeto, J. N. R., Withagen-Hermans, C. J., Nieuwlaat, A., Halley, D. J. J., \& van den Ouweland, A. M. W. (2014). A clinical and genetic overview of 18 years neurofibromatosis type 1 molecular diagnostics in The Netherlands. Clinical Genetics, 85(4), 318-327.

Vanderstappen, J., Lammens, J., Berger, P., \& Laumen, A. (2015). Ilizarov bone transport as a treatment of congenital pseudarthrosis of the 
tibia: A long-term follow-up study. Journal of Children's Orthopaedics, 9(4), 319-324.

Wu, X., Chen, S., He, Y., Rhodes, S. D., Mohammad, K. S., Li, X., \& Yang, F. C. (2011). The haploinsufficient hematopoietic microenvironment is critical to the pathological fracture repair in murine models of neurofibromatosis type 1. PLoS One, 6(9), e24917.

Young, H., Hyman, S., \& North, K. (2002). NF1: Clinical review and exceptions to the rules. Journal of Child Neurology, 17(8), 613-621.

Zhang, W., Rhodes, S. D., Zhao, L., He, Y., Zhang, Y., Shen, Y., \& Yang, F.-C. (2011). Primary osteopathy of vertebrae in a neurofibromatosis type 1 murine model. Bone, 48(6), 1378-1387.

\section{SUPPORTING INFORMATION}

Additional supporting information may be found online in the Supporting Information section.

How to cite this article: Brekelmans C, Hollants S, De Groote C, et al. Neurofibromatosis type 1-related pseudarthrosis: Beyond the pseudarthrosis site. Human Mutation. 2019;1-8. https://doi.org/10.1002/humu.23783 